\title{
Hemospray for arterial hemorrhage following endoscopic ultrasound-guided pseudocyst drainage
}

An 80-year-old man with alcoholic liver cirrhosis and obstructed jaundice due to a large pancreatic pseudocyst was referred for endoscopic ultrasound (EUS)guided cystogastrostomy. A computed tomography scan of the abdomen confirmed a $20-\mathrm{cm}$ pancreatic pseudocyst, which was compressing the stomach and biliary tree, as well as a moderate amount of ascites and portal thrombosis with signs of portal hypertension [1]. The platelet count was $70000 / \mathrm{mm}^{3}$. EUS confirmed the large pseudocyst adhering to the stomach wall. Cystogastrostomy was performed, and a double pigtail catheter $(10 \mathrm{Fr}, 10 \mathrm{~cm})$ was placed across the gastrocystic fistula.

After 10 hours, the patient complained of severe hematemesis with a significant drop in hemoglobin. Emergency endoscopy revealed a large amount of blood and clots in the gastric fundus, with active bleeding from a vessel in the margin of the gastric fistula ( Fig. 1). The catheter was not visualized and the fistula appeared to be closed. Adrenalin and fibrin glue were injected with an apparent cessation of bleeding; however, 4 hours later, the patient experienced two episodes of hematemesis of large amount of fresh blood. A second endoscopy was performed and confirmed the active bleeding. A decision was made to apply Hemospray (Cook Medical, Winston Salem, North Carolina, USA), which resulted in immediate hemostasis ( Fig. 2 and Fig.3, Video 1 ). The patient recovered well and no further episodes of bleeding occurred.

Hemospray acts by forming a barrier over the bleeding site and increasing local concentration of clotting factors [1]. Its efficacy has been shown in peptic ulcer bleeding [2], in cancer-related gastrointestinal bleeding, and in patients undergoing antithrombotic therapy $[3,4]$. These initial reports are very promising in terms of in-

\section{Video 1}

Active bleeding from a vessel in the margin of the gastric fistula was treated by application of Hemospray, which resulted in immediate hemostasis. itial hemostasis and rates of rebleeding, but are limited by the small number of published cases.

In the present case, Hemospray was used for very severe bleeding after cystogastrostomy in a patient with liver cirrhosis and portal hypertension, and the need for additional endoscopic or radiologic treatments was obviated simply by spraying the material onto the bleeding vessel.

\section{Endoscopy_UCTN_Code_TTT_1AO_2AN}

\section{Competing interests: None}

\section{Ilaria Tarantino, Luca Barresi, Antonino Granata, Gabriele Curcio, Mario Traina}

Department of Gastroenterology,

IsMeTT/UPMC, Palermo, Italy

\section{References}

1 Holster IL, De Maat MP, Ducharme R et al. In vitro examination of the effects of the hemostatic powder (hemospray) on coagulation and thrombus formation in humans. Gastrointest Endosc 2012; 75: AB240

2 Ung JJY, Luo D. Early clinical experience of the safety and effectiveness of Hemospray in achieving hemostasis in patients with acute peptic ulcer bleeding. Endoscopy 2011; 43: 291 - 295

3 Weusten B, Bergman JJ. A hemostatic spray: the easy way out for upper gastrointestinal bleeding? Endoscopy 2011; 43: 343-344

4 Holster IL, Kuipers EJ. Hemospray in the treatment of upper gastrointestinal hemorrhage in patients on antithrombotic therapy. Endoscopy 2013; 45: 63-66

\section{Bibliography}

Dol http://dx.doi.org/

10.1055/s-0033-1359164

Endoscopy 2014; 46: E71

(c) Georg Thieme Verlag KG

Stuttgart · New York

ISSN 0013-726X

\section{Corresponding author}

\section{Ilaria Tarantino}

Department of Gastroenterology

IsMeTT/UPMC

via trcomi Palermo 90100

Italy

Fax: +39-091-6665340

itarantino@ismett.edu

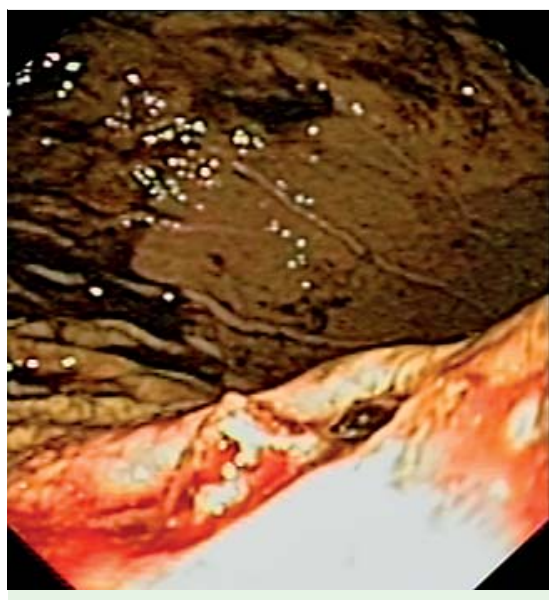

Fig. 1 Active bleeding from a vessel in the margin of the gastric fistula.

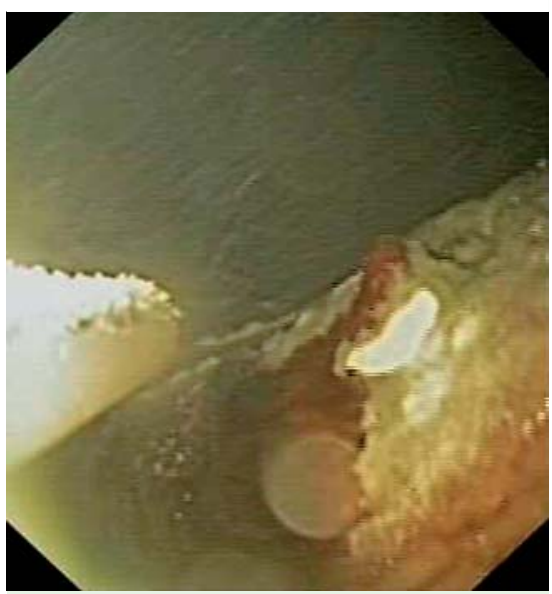

Fig. 2 Endoscopic treatment with Hemospray.

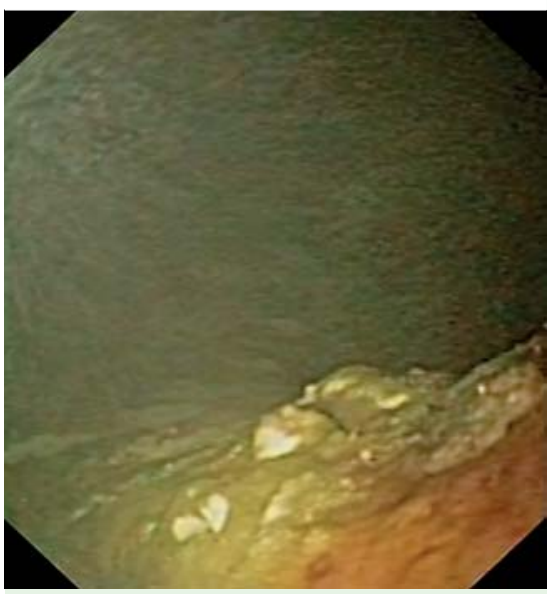

Fig.3 Immediate hemostasis after Hemospray treatment. 